\title{
Correction to: Dwelling in failure: power and uncertainty in a socialist large housing estate regeneration program in Saint Petersburg, Russia
}

\author{
Ekaterina Korableva ${ }^{1}$ D $\cdot$ Irina Shirobokova ${ }^{1} \cdot$ Oleg Pachenkov $^{2} \cdot$ Matthias Bernt $^{3}$
}

Published online: 6 December 2021

(c) Springer Nature B.V. 2021

\section{Correction to: Journal of Housing and the Built Environment https://doi.org/10.1007/s10901-021-09892-3}

In the original publication of the article, the funding information "This article is based on the research project "Estates After Transition" which is collaboratively funded by the German Federal Ministry of Education (Funding No. 01DJ18002) and the Russian Foundation for Basic Research (RFBR contract No. 18-511-76001) within the funding scheme "ERA.NET Plus with Russia - strengthening STI links between Russia and the European Research Area" was inadvertently missed.

The missing funding information has been included.

The original article has been corrected.

Publisher's Note Springer Nature remains neutral with regard to jurisdictional claims in published maps and institutional affiliations.

The original article can be found online at https://doi.org/10.1007/s10901-021-09892-3.

Ekaterina Korableva

korablevaed@gmail.com

1 Center for Independent Social Research (CISR), Saint Petersburg, Russia

2 Center for Applied Research (CeAR), European University at St. Petersburg, Saint Petersburg, Russia

3 Leibniz Institute for Research on Society and Space, Erkner, Germany 